\title{
Zaznavanje razvoja trajnostnega kmetijstva
}

UDK: $631(045)$

\author{
Maja Klun \\ Univerza v Ljubljani, Fakulteta za upravo \\ maja.klun@fu.uni-lj.si \\ Renata Slabe Erker \\ Inštitut za ekonomska raziskovanja \\ erkerr@ier.si

\section{IZVLEČEK}

V konceptu trajnostnega kmetijstva se srečujeta obe področji upravljanja Ministrstva za kmetijstvo in okolje, z vsemi družbenimi implikacijami. Kot prispevek k oblikovanju, izvajanju in vrednotenju trajnostnih aktivnosti analiziramo $v$ članku odnos javnosti in kmetov do trajnostnega razvoja v kmetijstvu. Rezultati raziskave kažejo, da obstaja v Sloveniji podpora trajnostnemu kmetijstvu ne le na deklarativni ravni, ampak tudi v javnosti. Statistično značilne razlike med podporo splošne javnosti in kmetov pa so v dojemanju trajnostnega napredka kmetijstva na področju okolja. Vzporedno se kaže neskladje med načelno in dejansko podporo trajnostnemu kmetijstvu. Zato bi bilo smiselno razmisliti o spremembi fokusa ukrepov kmetijske politike iz okoljske na družbeno trajnost in preživetje kmeta, ob poudarjanju pozitivnih okoljskih informacij o slovenskem kmetijstvu.

$\begin{aligned} & \text { Ključne besede: } \text { trajnostni razvoj kmetijstva, zaznavanje, javnost, kmetje, kazalniki } \\ & \text { trajnostnega kmetijstva }\end{aligned}$ JEL: Q18, Q01

\section{Uvod}

Trajnostni razvoj, katerega sestavni del je tudi trajnostno kmetijstvo, je eden glavnih dolgoročnih prednostnih ciljev Evropske unije, usmerjen k večji kakovosti življenja ljudi. S svojo gospodarsko, okoljsko in družbeno vlogo se sooča z izzivi Lizbonske strategije (2000), kajti njen temeljni cilj - nova kakovostna delovna mesta in večja konkurenčnost - se lahko uresničuje v raznoliki državi kot je Slovenija, prav z razvojem podeželja. V tem smislu ustvarja trajnostno kmetijstvo ne le neposredne in posredne zaposlitve na 
Maja Klun, Renata Slabe Erker

lokalnih ravneh in širše, v sinergiji z drugimi gospodarskimi dejavnostmi, temveč je vir zdrave in varne hrane, osnovni pogoj ohranjanja biotske raznovrstnosti in krajinske pestrosti, ohranja poseljenost podeželja, je temelj sonaravnega turizma ter omogoča udejanjanje drugih okoljskih in družbenih funkcij prostora, kot so ekosistemske, estetske, kulturne in rekreacijske, ki povečujejo kakovost življenja.

Evropska unija se je na deklarativni ravni odločila za trajnostni razvoj in v tem okviru tudi za trajnostno kmetijstvo. Zato mednarodne in nacionalne institucije, kot so Organizacija Združenih narodov za prehrano in kmetijstvo - FAO, in področna ministrstva za kmetijstvo spodbujajo kmete k izvajanju prakse trajnostnega kmetijstva, širšo javnost pa k sprejemanju te prakse. Pogoj za vzpostavitev takšnega odnosa do kmetijstva pa je vnaprejšnje zaupanje in védenje, da so te prakse resnično koristne (Tathdil et al., 2009).

Tudi prihodnja skupna kmetijska politika (Evropska Komisija, 2012) bo morala biti trajnostno naravnana, uravnotežena, ciljno usmerjena, učinkovita in odgovorna. Kmetijstvo namreč desetletja izgublja svoj gospodarski pomen (kar se odraža npr. v deležu BDP), ohranja svoje prostorske in družbene razsežnosti, vse bolj pa ponovno postaja pomembna osnovna pridelovalna funkcija kmetijstva oziroma hrana kot strateška dobrina. Ključni izzivi nove kmetijske politike $v$ naslednjem programskem obdobju so zato prehranska varnost, trajnostno upravljanje naravnih virov in uravnotežen ozemeljski razvoj.

Stopnja legitimnosti in sprejemljivosti družbenega cilja, v našem primeru trajnostnega kmetijstva, se povečuje z odprtostjo javne uprave tako, da zna le-ta prisluhniti mnenju državljanov o stanju in izvajanju politike. Zato je pomembno vedeti, kakšen je odnos javnosti do trajnostnega razvoja $v$ kmetijstvu, kako javnost trajnost razume in kakšen pomen ji pripisuje. Poleg tega pa je tudi pomembno identificirati dejavnike, ki vplivajo na to zaznavanje. Zelo težko je namreč učinkovito in odgovorno izvajati politiko, če le-ta nima ustrezne podpore v javnosti, če ni razumljiva ali dovolj promovirana. $\checkmark$ demokratičnih sistemih praviloma državni organi želijo pridobiti odziv javnosti na stanje/odločitve (in tudi strokovno podlago za svoje odločitve), čeprav se vključevanje oziroma vplivanje javnosti na javnopolitične odločitve lahko odraža v končni politični volji zelo omejeno. S tem člankom poskušamo zapolniti vrzel $v$ empiričnem raziskovanju javnega mnenja o trajnostnem kmetijstvu $v$ Sloveniji in soočanju le-tega z dejanskim stanjem, o katerem pričajo kazalniki trajnostnega kmetijstva.

Enotne definicije trajnostnega kmetijstva v tem trenutku ni. Gre boljza filozofijo oz. način kmetovanja in hkrati tudi življenja, znotraj katerega so mogoče različne interpretacije in razumevanje. Ker pa se pojem trajnosti nanaša na enakovredno upoštevanje okoljske, družbene in ekonomske komponente v razvoju, bi moralo to veljati tudi za trajnostno kmetijstvo. Vendar je na primer že interpretacija trajnostnega razvoja kmetijstva v Zakonu o kmetijstvu (Ur. list 
RS, št. 45/2008, 15. člen) zožena na okoljski segment: »trajnostno kmetijstvo vzdržuje biotsko raznovrstnost živalskih in rastlinskih vrst in ohranja tla ter njihovo rodovitnost ob varovanju naravnih razmer za življenje v tleh, vodi in zraku«. Takšna interpretacija bi bolj prisodila ekološkemu kmetijstvu, kjer je poudarjena okoljska (ekološka) trajnost.

Čeprav je kmetijstvo primarno povezano s podnebjem, prstjo, zemljišči, vodo, gozdovi, biotsko raznolikostjo, pridelavo poljščin in živalmi, pa ne gre pozabiti tudi na njegovo povezavo s kmeti, ruralnimi skupnostmi, revščino in drugimi družbenimi problemi. Zato trajnostna rast kmetijstva ne vpliva samo na proizvodnjo hrane in rabo naravnih virov, ampak je pomembna tudi za dobrobit ljudi v kmečki skupnosti in za družbo kot celoto. $\vee$ tem smislu je treba pogled na trajnostno kmetijstvo nujno razširiti.

Ikerd (1996) je trajnostno kmetijstvo opredelil širše, to je kot okolju prijazno oz. neškodljivo z vidika rabe naravnih virov, ekonomsko upravičeno, družbeno podprto ter konkurenčno. Podobno, celovito interpretira trajnost tudi Plut (2004). Trajnostni razvoj zahteva premik v smer gospodarskega napredka glede omejitev okolja, hkrati pa mora stremeti k omogočanju zadovoljevanja potreb sedanjih generacij ob predpostavki, da ne ogroža življenja prihodnjih generacij (tako ljudi kot rastlinskih in živalski vrst). Tako se v smislu trajnostnega razvoja kmetijstva zaznamuje odnos do narave, sposobnosti samoobnavljanja le-te kot tudi v odnosu do človeka in njegovih psihičnih in fizičnih zmogljivosti (Plut, 2004).

Zelo celovita je zakonska opredelitev trajnostnega kmetijstva ameriške vlade iz leta 1990 (Public Law 101-624, Title XVI, Subtitle A, Section 1683), in sicer kot »celovit sistem pridelovanja rastlin in vzreje živali v skladu z značilnostmi pridelovalnega območja, ki dolgoročno zagotavlja: (i) zadovoljevanje potreb po hrani za ljudi in živali, (ii) izboljšanje stanja okolja in tistih naravnih virov, ki so ključni za obstoj kmetijstva, (iii) najbolj optimalno rabo neobnovljivih virov in virov na sami kmetiji, (iv) vključuje naravni biološki krogotok in nadzor, (v) vzdržuje ekonomsko živost kmetijske proizvodnje in (v) izboljšuje kakovost življenja kmetov in družbe nasploh«.

Kako široko trajnostno kmetijstvo razumejo širša javnost in kmetje $v$ Sloveniji, smo želeli ugotoviti z našo raziskavo. Poleg tega nas je zanimalo, kako ocenjujejo pomembnost razvoja trajnostnega kmetijstva s pomočjo različnih funkcij in ciljev kmetijske politike ter ali med širšo javnostjo in kmeti prihaja do razlik o mnenju, kako pomemben je v resnici trajnostni razvoj kmetijstva. $\mathrm{V}$ raziskavi smo uporabili metodo analize primarnih podatkov, ki smo jih pridobili na podlagi opravljenih anket med dvema ciljnima skupinama. Rezultate javnega mnenja primerjamo še z dejanskim stanjem, to je z kazalniki trajnostnega kmetijstva. 
Maja Klun, Renata Slabe Erker

V članku je najprej predstavljen pregled podobnih raziskav v tujini in doma. Sledijo prikaz metodologije in vprašalnika ter rezultati raziskave. Zaključi pa se članek s temeljnimi ugotovitvami, implikacijami za prakso in razpravo.

\section{Pregled do sedaj opravljenih raziskav}

Kljub velikemu poudarku na politikah spodbujanja trajnostnega kmetijstva je bilo v praksi opravljenih malo raziskav o tem, kako ga dojemajo različne ciljne populacije. Merjenje zaznavanja javnosti ter dejavnikov, ki vplivajo na mnenje, bi moral biti obvezen predhodni korak pri razvoju programov informiranja in osveščanja javnosti o pomenu trajnostnega kmetijstva v prostoru in družbi (Tathdil et al., 2009).

Eurobarometer spremlja na ravni EU javno mnenje tudi o trajnostnem kmetijstvu. Rezultati kažejo, da državljani EU vidijo kot najpomembnejši vidik politike trajnostnega kmetijstva zagotavljanje socialne stabilnosti kmetov (Special Eurobarometer, 2008), kar se ujema z rezultati naše raziskave na vzorcu populacije kmetov, predstavljenimi v nadaljevanju.

Parcialne študije o zaznavanju trajnostnega kmetijstva so bile izvedene tako v Evropi kot tudi drugje po svetu, saj je to področje interesa različnih družbenih sfer (od politike, znanstvene sfere, gospodarstva, ipd.), pri čemer so se raziskovalci osredotočali na različne dejavnike. Bolj celostna raziskava, ki je zelo podobna v nadaljevanju predstavljeni raziskavi za Slovenijo, pa je bila izvedena v Turčiji (Tathdil et al., 2009). Osnovni namen te študije je bil kvantitativno določiti dojemanje trajnostnega kmetijstva med kmeti ter ugotoviti, kako na to vplivajo različni družbenoekonomski dejavniki in informiranost kmetov. Družbenoekonomske značilnosti so zajemale kmetijski sistem, območje kmetije, pripadnost zadrugam in drugim organizacijam v lokalni skupnosti, starost, izobrazbo in dohodek kmeta. $V$ komponento informiranosti in iskanje informacij pa so bili vključeni uporaba množičnih medijev (časopisi, radio, televizija), uporaba interneta, potovanja in udeležba na kmetijskih konferencah. Rezultati študije so pokazali, da višji družbenoekonomski status in boljši dostop do informacij pomeni, da kmetje pripisujejo večji pomen trajnostnemu kmetijstvu. Če bi se torej oblikovalci politik in druge kompetentne organizacije osredotočile na demografsko ciljane informacijske ukrepe, bi lahko kmete bolj uspešno usmerili v naklonjenost trajnostnemu kmetovanju.

Aerni (2009) v svoji raziskavi opozarja, da javne razprave o trajnostnem kmetijstvu ponavadi oblikujejo prevladujoče politične interesne skupine, ki hkrati prispevajo k oblikovanju javnega mnenja in se odzivajo nanj. Preverjal je, $v$ kolikšni meri je odnos teh skupin povezan z mnenjem javnosti o trajnostnem kmetijstvu in kako se te predstave razlikujejo med državami z različnimi kmetijskimi politikami. Izvedeni sta bili dve raziskavi zaznavanja trajnostnega kmetijstva, in sicer v Švici in na Novi Zelandiji. Analiza podatkov je pokazala, da obstajajo precejšnje razlike $v$ dojemanju trajnosti med državljani obeh 
držav. Medtem ko so v Švici menili, da je švicarsko kmetijstvo že sedaj precej trajnostno naravnano, so anketiranci v Novi Zelandiji večinoma menili, da bi morali uvesti določene gospodarske in tehnološke spremembe, da bi bilo kmetijstvo bolj trajnostno naravnano. Rezultati so v skladu s tem, da je v Švici kmetijska politika bolj defenzivna, medtem ko je pristop v Novi Zelandiji bolj povezan s politiko trajnostnega kmetijstva , ki je povezana s konkurenčnostjo gospodarstva države kot celote.

Študije v državah v razvoju so zelo specifične glede vključevanja dejavnikov, ki vplivajo na zaznavanje trajnostnega razvoja kmetijstva. Skupno vsem pa je, da ugotavljajo občutljivost javnosti na zmanjševanje revščine, doseganje trajnostne rabe naravnih virov, nadzor erozije in degradacije tal, pravilno uporabo gnojil in pesticidov ter vlaganje $v$ raziskave in širjenje storitev (Bhutto \& Bazmi, 2007). Na primer Rao in Hall (2003) sta izvedla študijo v Indiji, podobno Rahman (2003) študijo v Bangladešu, kjer so ugotovili, da so razlogi za oteževanje zmanjševanja revščine in uvajanja trajnostnega razvoja v kmetijstvu bodisi v pomanjkanju državnih sredstev ali negativnega dojemanja sodobnih kmetijskih tehnologij med kmeti. Ti verjamejo, da ima sodobna tehnologija škodljive vplive na okolje, kot je na primer nižja rodovitnost zemlje, škodljive vplive na zdravje in na večjo pojavnost bolezni pri rastlinah (Tathdil et al., 2009). Podobno je tudi v drugih državah tretjega sveta (nрг. Taylor et al., 1993, za Malezijo).

Medtem ko se v prej omenjenih državah soočajo s pomanjkanjem poznavanja koncepta trajnostnega kmetijstva, študije $v$ ZDA kažejo na drugačne probleme. Alonge in Martin (1995) sta ugotovila, da se kmetje po eni strani sicer bolj zavedajo in poznajo negativne okoljske in socialne posledice konvencionalnega kmetijstva, po drugi strani pa se to ne kaže v sprejemanju in izvajanju trajnostnih kmetijskih praks. Poskusi, da bi pojasnili nizko stopnjo uveljavljanja trajnostnih kmetijskih praks, so bili številni in raznoliki. Pogosto se ta pojasnjuje z na primer željo po večji produktivnosti z uporabo strojev, ki pa so bili škodljivi za okolje (Swanson et al., 1986; Napier et al., 1984). Študije v ZDA so preučevale mnoge mogoče vplive na sprejemanje novega načina kmetovanja, ki so obsegali ekonomske, družbene, fizične in tehnične vidike kmetovanja. Rao in Rogers (2006) sta poudarila pomen naslednjih dejavnikov: zaznavanje tveganja in dobičkonosnosti, gotovost in negotovost glede sprejemanja trajnostnega kmetovanja, obseg potrebnih informacij ter odnos do trajnostnega kmetovanja. Identificirani so bili tudi nekateri vplivni dejavniki, kot so demografski dejavniki, znanje, zavedanje, skupinska miselnost, tehnološke značilnosti in informiranost. Rezultati so pokazali pozitivno in močno povezanost med starostjo, izkušnjami s kmetovanjem, izobrazbo in družbenoekonomskim statusom, intenzivnostjo obdelave, motivacijo, inovativnostjo, uporabo informacij ter sprejemanjem novega načina trajnostnega kmetovanja (Hosseini et al., 2011).

V Sloveniji sta se Juvančič in Slabe Erkerjeva (2006) ukvarjala z vprašanjem, v kolikšni meri so politični instrumenti usklajeni z javnim interesom na področju 
večnamenskega kmetijstva. Rezultati raziskave so pokazali, da je široka politična podpora za trajnostno upravljanje zemljišč in ohranjanje podeželja v Sloveniji na splošno v skladu s preferencami javnosti. $V$ nasprotju s tem pa javnost daje visoko prioriteto vidiku varne in kakovosti hrane, medtem ko je podpora politike temu vidiku nizka.

\section{Metodologija}

Podatkovni niz za našo raziskavo dobimo iz ankete, izvedene v okviru raziskovalnega projekta »Parametri trajnostnega razvoja kmetijstva« (2012). Za pridobivanje podatkov sta uporabljena dva različna vprašalnika, ki se razlikujeta po tem, ali so odgovarjale osebe, ki imajo doma kmetijo, ali širša javnost. Opazovane enote iz prvega in drugega vprašalnika razumemo kot dva neodvisna vzorca, vzorec »javnost« in vzorec »kmetje«.

Za testiranje domneve, da se odnos javnosti in kmetov do trajnostnega kmetijstva v Sloveniji ne razlikuje, uporabimo Mann-Whitney neparametrični test za dva neodvisna vzorca. Gre za test, ki je ekvivalenten t-testu in se uporabi, kadar imamo opravka z opisnimi spremenljivkami na ordinalni skali. Za izračun testne statistike se uporabijo vrednosti rangov. Zato se številske spremenljivke pretvorijo v range, tako da se najmanjši vrednosti pripiše najnižji rang. Mann-Whitney test temelji na testni statistiki $U$, opredeljeni za skupino $i$ z: (Mann \& Whitney, 1947)

$$
U_{i}=n_{1} n_{2}+\frac{n_{1}\left(n_{1}+1\right)}{2}-R_{i}
$$

kjer je $R_{i}$ vsota rangov skupine $i$.

\subsection{Vprašalnik}

Zaradi lažje statistične obdelave podatkov so vprašanja v anketi zaprtega tipa z vnaprej ponujenimi odgovori. Vprašalnika za širšo javnost in kmete zajemata pet vsebinskih vprašanj z več trditvami, pri čemer vprašani izrazijo stopnjo strinjanja ali nestrinjanja v zvezi z obravnavano zadevo na petstopenjski lestvici. Evalvirano je bilo torej samo zaznavanje anketiranih, saj so ti pri vprašanjih podajali zgolj ocene na postavljene trditve. Zadnje, šesto vprašanje, vsebuje splošna demografska vprašanja o anketirancu, ki so spol, starost, izobrazba in regija bivanja. Vprašalnik, ki je apliciran na ciljno skupino kmečke populacije, ima še dve dodatni vsebinski vprašanji ter dve dodatni demografski vprašanji v zvezi z velikostjo kmetije glede na katastrski dohodek in prevladujočo usmeritvijo na kmetiji.

Z vprašalnikom smo želeli preveriti, kaj od predstavljenih široko opredeljenih vsebin po mnenju anketirancev najbolj odraža trajnostno kmetijstvo, kako visoko anketiranci postavljajo trajnostni razvoj v kmetijstvu v primerjavi z drugimi družbenimi področji, pomembnost določenih funkcij oz. ciljev 
kmetijstva. $V$ naslednjem sklopu vprašanj so anketiranci ocenjevali razvojno komponento trajnostnega kmetijstva. Podali so oceno razvoja kmetijstva v Sloveniji v zadnjih deset letih z vidika preskrbe s hrano, preživetja kmeta in ohranjanja okolja ter ovrednotili posamezne razloge za smer razvoja, ki so ga označili.

Anketiranje je potekalo od novembra 2011 do konca februarja 2012. Izbran je bil naključni vzorec ljudi, kjer je bilo upoštevano, da so bili primerno razporejeni glede na spol, starost, izobrazbo in regijo, pri populaciji kmetov pa še glede na velikost in dejavnost kmetije. Izbor enot v vzorec je vključeval osebe, ki so bile pripravljene sodelovati pri anketi. Ta je potekala osebno.

Izpolnjenih je bilo 507 anket za širšo javnost in 329 anket za populacijo kmetov, kar pomeni skupaj 836 anket. Pri anketah med širšo javnostjo je bilo ugotovljeno, da pet vprašalnikov ni bilo izpolnjenih v celoti, zato ti v analizi niso upoštevani. Enako število nepopolnih anket je bilo tudi v primeru anketiranja populacije kmetov.

\subsection{Opisne statistike}

V podatkovni bazi imamo na voljo 826 veljavnih opazovanj (v nadaljevanju: vzorec). Večina, to je okoli tretjina anketirancev, iz vzorca »javnostu in dobra četrtina anketirancev iz vzorca »kmetje» prihaja iz Osrednje slovenske regije. Druga najbolj pogosto zastopana regija pa je jugovzhodna Slovenija. Struktura anketirancev po regijah ustreza strukturi prebivalstva po regijah. Slabih $80 \%$ anketirancev v vsakem vzorcu je starih od 24 do 64 let. $V$ populaciji je ta, sicer široka, starostna skupina zastopana z dvotretjinskim deležem starejših od 64 let je skoraj $20 \%$, mladih pa okoli $8 \%$. To kaže na problematičnost našega vzorca z vidika starostne strukture, saj starejši niso želeli odgovarjati na vprašanja. Ženske so v vzorcu »javnost« zastopane le nekoliko bolj kot v populaciji, kjer jih je slabih $51 \%$. V vzorcu »kmetje« pa le z dobrimi $40 \%$. Takšen odziv je pri kmetijskih raziskavah pričakovan. Pri anketirancih iz vzorca »javnost« prevladuje višja in visokošolska stopnja izobrazbe, saj je teh anketirancev več kot polovica (v populaciji okoli $20 \%$ ), srednjo izobrazbo ima 31,1 \% anketirancev (v populaciji okoli $32 \%$ ), sledi $11 \%$ tistih z magisterijem in doktoratom ter 3,4 \% tistih z osnovnošolsko izobrazbo (v populaciji okoli $20 \%$ ). V našem vzorcu »javnost« so glede na populacijo nadpovprečno zastopani anketiranci z višjo in visokošolsko izobrazbo na račun tistih z osnovnošolsko izobrazbo, ki niso želeli odgovarjati na vprašanja. V vzorcu »kmetje« prevladuje srednja izobrazba, saj je teh anketirancev približno polovica, sledi pa dobra tretjina anketirancev $z$ višjo in visokošolsko izobrazbo. Glede na opažene razlike v demografskih značilnosti vzorca smo morebitne razlike v posameznih odgovorih preverili tudi glede na te značilnosti in ugotovili, da odgovori statistično značilno ne variirajo med različnimi anketiranci glede na spol, starost, izobrazbo ali regijo bivanja. 
Maja Klun, Renata Slabe Erker

Tabela 1: Družbenoekonomske lastnosti vzorca anketirancev

\begin{tabular}{|c|c|c|c|c|}
\hline & \multicolumn{2}{|c|}{ Širša javnost $(N=502)$} & \multicolumn{2}{|c|}{ Kmečka gospodinjstva (N=324) } \\
\hline Spremenljivka & $\begin{array}{l}\text { 1. najbolj } \\
\text { frekventni } \\
\text { odgovor }\end{array}$ & $\begin{array}{l}\text { 2. najbolj } \\
\text { frekventni } \\
\text { odgovor }\end{array}$ & $\begin{array}{l}\text { 1. najbolj } \\
\text { frekventni } \\
\text { odgovor }\end{array}$ & $\begin{array}{l}\text { 2. najbolj } \\
\text { frekventni } \\
\text { odgovor }\end{array}$ \\
\hline Regija & $\begin{array}{l}\text { Osrednje- } \\
\text { slovenska } \\
(33,5 \%)\end{array}$ & $\begin{array}{l}\text { Jugovzhodna } \\
(13,1 \%)\end{array}$ & $\begin{array}{l}\text { Osrednje- } \\
\text { slovenska } \\
(25,9 \%)\end{array}$ & $\begin{array}{l}\text { Jugovzhodna } \\
(16 \%)\end{array}$ \\
\hline $\begin{array}{l}\text { Starostna } \\
\text { skupina }\end{array}$ & $24-44(56,6 \%)$ & $44-64(21,9 \%)$ & $44-64(40,5 \%)$ & $24-44(40,1 \%)$ \\
\hline Spol & ženski $(61,8 \%)$ & moški $(35,7$ \%) & moški $(56,5 \%)$ & ženski $(43,5 \%)$ \\
\hline Izobrazba & $\begin{array}{l}\text { višja in } \\
\text { visokošolska } \\
(52 \%)\end{array}$ & srednja $(31,1 \%)$ & srednja $(50,2 \%)$ & $\begin{array}{l}\text { višja in } \\
\text { visokošolska } \\
(36,1 \%)\end{array}$ \\
\hline
\end{tabular}

$\checkmark$ vzorcu »kmeti« prevladujejo po velikosti tiste kmetije, ki dosegajo med $1000 €$ in $2500 €$ katastrskega dohodka (KD), sledi skupina kmetov katerih KD dosega med $500 €$ in $1000 €, 18,1 \%$ je tistih, katerih KD je $v$ razponu med $2500 €$ in $7500 €, 15,4 \%$ tistih, ki imajo KD med $200 €$ in $500 €$, najmanj je tistih nad $7500 €$ KD (8\%). Glede na prevladujočo dejavnost na kmetiji, prevladujejo mešane kmetije, sledijo kmetije, na katerih prevladuje živinoreja (33 \%), 9,4 \% kmetij je pretežno usmerjenih na poljedelstvo, trajni nasadi so prevladujoči pri $8 \%$ anketirancev. $\vee$ našem vzorcu je več mešanih kmetij in manj poljedelcev kot v populaciji. Po podatkih SURS-a je namreč v Sloveniji kmetij s prevladujočo živinorejo dobrih $56 \%$, kmetij s prevladujočim poljedelstvom pa $22 \%$. Razlike $v$ odgovorih so bile zato preverjene tudi glede na te značilnosti in statistično značilnih razlik nismo ugotovili.

\section{Rezultati}

\subsection{Razumevanje trajnostnega kmetijstva}

Visoke povprečne ocene vseh trditev o tem, kaj najbolj označuje trajnostno kmetijstvo, in rezultati neparametričnega $\chi^{2}$ testa za vsako od trditev, ki potrjujejo statistično značilne razlike med opazovanimi in pričakovanimi frekvencami $(p=0,000)$, dokazujejo, da javnost in kmetje v splošnem široko in enako pomembno razume vse vidike kmetijske trajnosti - okoljsko, družbeno in ekonomsko. Povprečne ocene trditev med obema skupinama anketirancev se le malenkostno razlikujejo (prim. grafikon 1). 
Grafikon 1: Primerjava povprečnih ocen trditev javnosti in kmetov o tem, kaj najbolj označuje trajnostno kmetijstvo

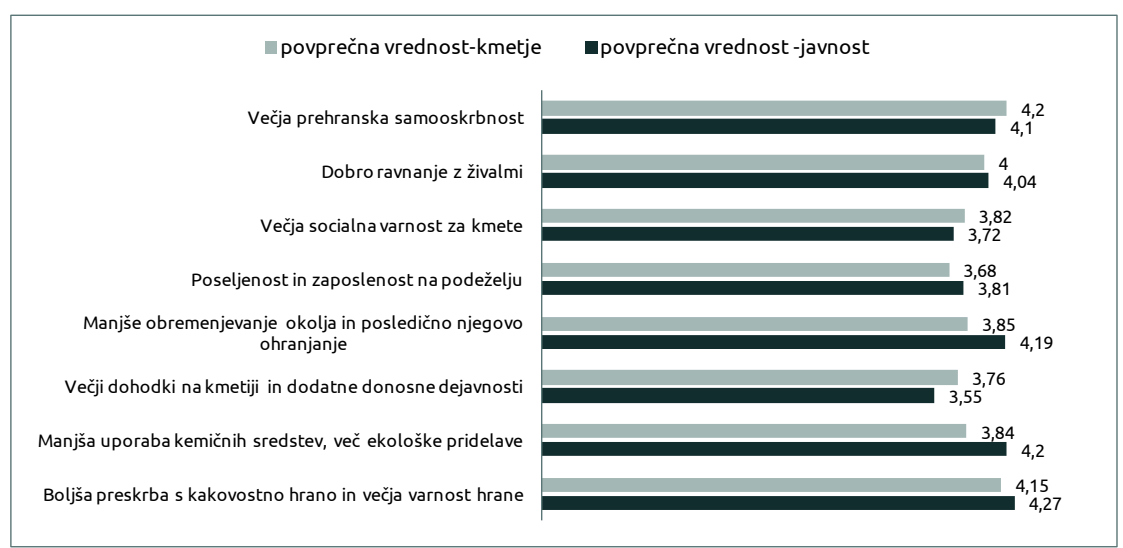

Mann-Whitney test je potrdil, da se odgovori statistično značilno razlikujejo med skupinama samo pri treh trditvah (tabela 2). Pri trditvah »manjša uporaba kemičnih sredstev, več ekološke pridelave« in »manjše obremenjevanje okolja in posledično njegovo ohranjanje« $(p=0,000)$ je večje strinjanje javnosti, pri trditvi »večji dohodki na kmetiji in dodatne donosne dejavnosti« $(p=0,002)$ pa je večje strinjanje kmetov. Splošna javnost pripisuje večji pomen okoljski determinanti trajnosti, kmetje pa ekonomski.

Tabela 2: Mann-Whitney test za trditve o tem, kaj najbolj odraža trajnostno kmetijstvo

\begin{tabular}{|l|r|r|r|r|}
\hline & $\begin{array}{r}\text { Mann- } \\
\text { Whitney U }\end{array}$ & Wilcoxon W & Z & $\begin{array}{r}\text { Asymp. } \\
\text { Sig. } \\
\text { (2-tailed) }\end{array}$ \\
\hline $\begin{array}{l}\text { Boljša preskrba s kakovostno } \\
\text { hrano in večja varnost hrane }\end{array}$ & 75865,000 & 128515,000 & $-1,715$ &, 086 \\
\hline $\begin{array}{l}\text { Manjša uporaba kemičnih } \\
\text { sredstev, več ekološke pridelave }\end{array}$ & 64993,500 & 117643,500 & $-5,131$ &, 000 \\
\hline $\begin{array}{l}\text { Večji dohodki na kmetiji in } \\
\text { dodatne donosne dejavnosti }\end{array}$ & 71279,000 & 197030,000 & $-3,079$ &, 002 \\
\hline $\begin{array}{l}\text { Manjše obremenjevanje okolja in } \\
\text { posledično njegovo ohranjanje }\end{array}$ & 68672,000 & 121322,000 & $-3,974$ &, 000 \\
\hline $\begin{array}{l}\text { Poseljenost in zaposlenost na } \\
\text { podeželju }\end{array}$ & 78695,000 & 131345,000 &,- 772 &, 440 \\
\hline Večja socialna varnost za kmete & 75628,000 & 201379,000 & $-1,726$ &, 084 \\
\hline Dobro ravnanje z živalmi & 78208,500 & 130858,500 &,- 934 &, 350 \\
\hline Večja prehranska samooskrba & 77986,000 & 203737,000 & $-1,021$ &, 307 \\
\hline
\end{tabular}


Maja Klun, Renata Slabe Erker

\subsection{Pomembnost trajnostnega kmetijstva glede na druga družbena področja in glede njegovih funkcij}

Povprečna ocena pomembnosti trajnostnega razvoja v kmetijstvu v primerjavi z drugimi družbenimi področji je zelo podobna pri obeh skupinah (grafikon 2).

\section{Grafikon 2: Pomembnost trajnostnega kmetijstva v primerjavi z drugimi} področji (ocene $1-5, \%$ )

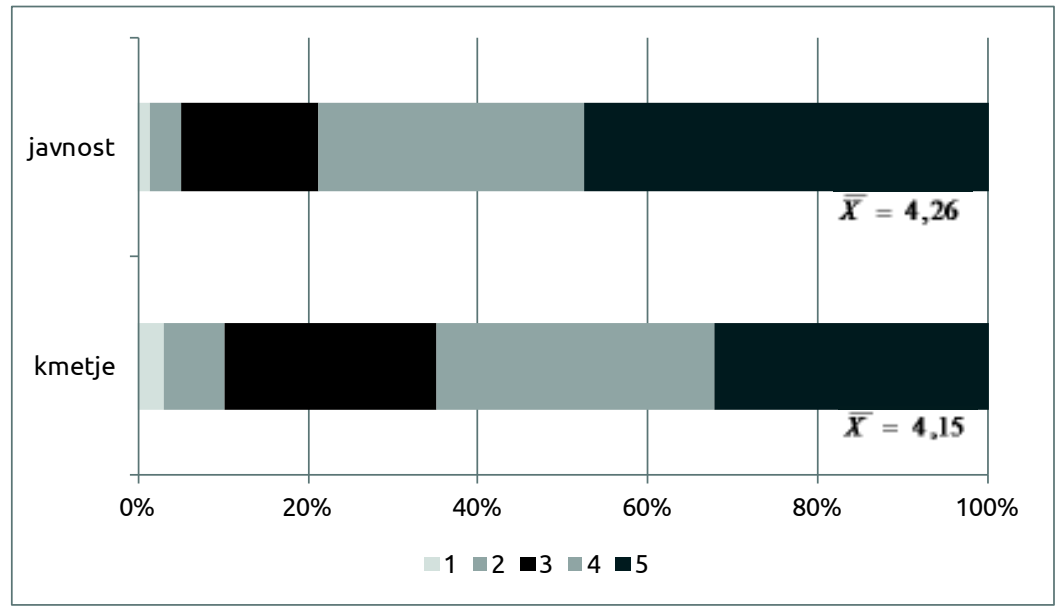

Rezultati Mann-Whitney testa tudi niso statistično značilni ( $p=0,147)$, kar pomeni, da pomembnost trajnostnega kmetijstva glede na druga družbena področja javnost in kmetje ocenjujejo enako.

Primerjava povprečnih ocen o pomembnosti posameznih funkcij oz. ciljev trajnostnega kmetijstva (grafikon 3) kaže, da se večje razlike vodgovorih kažejo pri oceni trditev »ohranjanje naravne in kulturne dediščine«, »nadzorovana uporaba gnojil in fitofarmacevtskih sredstev«, »stabilizacija in dvig dohodka«, »zmanjševanje kmetijskega obremenjevanja okolja« in pri trditvi »zaščita in ohranjanje kvalitetne vode, ohranjanje tal in prsti«. Trditev »stabilizacija in dvig dohodka« so bolje ocenili kmetje, medtem ko je druge trditve z okoljsko vsebino bolje ocenila splošna javnost. 


\section{Grafikon 3: Primerjava povprečnih ocen pomembnosti javnosti in kmetov o} funkcijah in ciljih kmetijstva

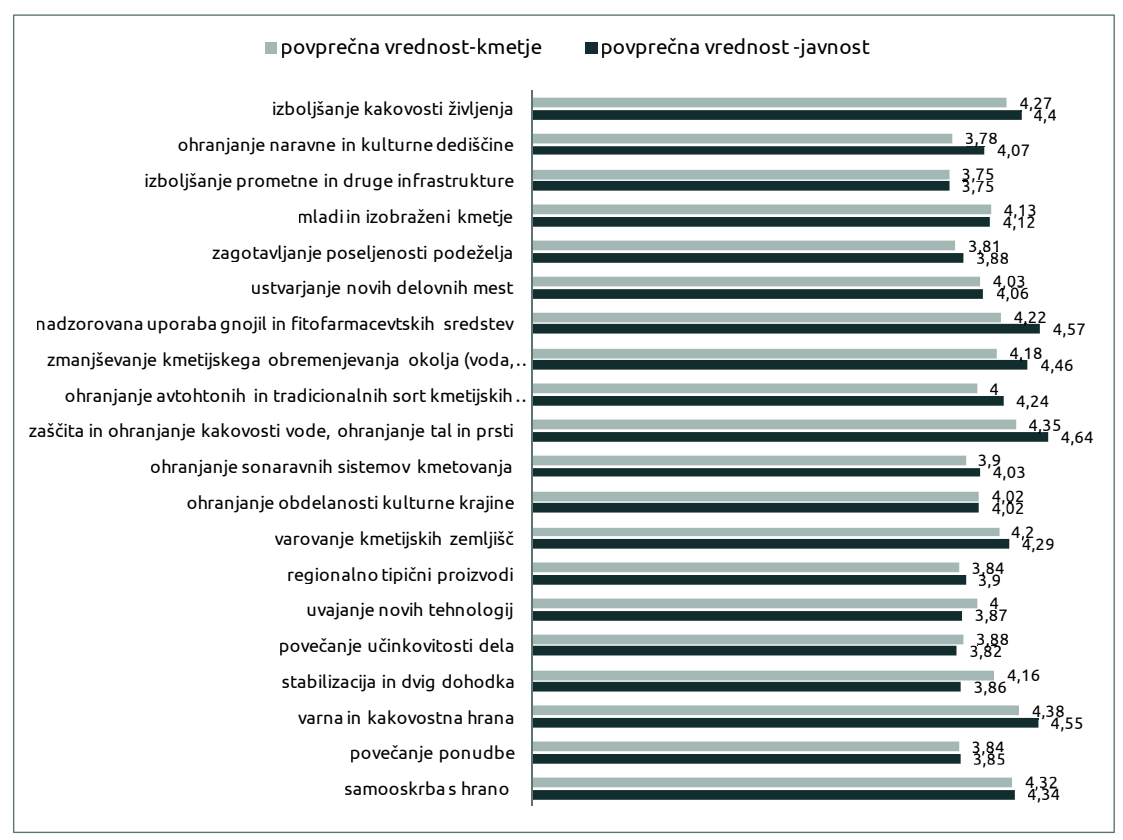

Za navedene trditve smo izdelali tudi Mann-Whitney test, s katerim smo želeli ugotoviti, ali se trditve statistično značilno razlikujejo med obema skupinama anketirancev. Iz tabele 3 je razvidno, da se odgovori statistično razlikujejo med skupinama pri trditvah, pri katerih smo že omenili opaznejše razlike povprečnih ocen $(p \approx 0,00)$, k tem pa lahko dodamo še dve trditvi: »varna in kakovostna hrana«, ki ji daje večjo pomembnost javnost, ter »ohranjanje avtohtonih in tradicionalnih sort kmetijskih rastlin in pasem živali«, ki mu dajejo večjo pomembnost kmetje. Ponovno se torej izkaže, da splošna javnost nekoliko višje vrednoti okoljsko dimenzijo trajnosti, kmetje pa ekonomsko. To kaže na konsitentnost anketirancev pri odgovarjanju na anketna vprašanja. 
Maja Klun, Renata Slabe Erker

Tabela 3: Mann-Whitney test za trditve o pomembnosti posameznih funkcij oz. ciljev kmetijstva

\begin{tabular}{|l|r|r|r|r|}
\hline & $\begin{array}{r}\text { Mann- } \\
\text { Whitney U }\end{array}$ & Wilcoxon W & Z & $\begin{array}{r}\text { Asymp. } \\
\text { Sig. } \\
\text { (2-tailed) }\end{array}$ \\
\hline samooskrba s hrano & 79901,000 & 132551,000 &,- 419 &, 675 \\
\hline povečanje ponudbe & 81012,500 & 133662,500 &,- 047 &, 962 \\
\hline varna in kakovostna hrana & 71695,500 & 124345,500 & $-3,287$ &, 001 \\
\hline stabilizacija in dvig dohodka & 64922,000 & 190673,000 & $-5,139$ &, 000 \\
\hline povečanje učinkovitosti dela & 77218,000 & 202969,000 & $-1,252$ &, 211 \\
\hline uvajanje novih tehnologij & 75143,000 & 200894,000 & $-1,898$ &, 058 \\
\hline regionalno tipični proizvodi & 78210,000 & 130860,000 &,- 929 &, 353 \\
\hline varovanje kmetijskih zemljičč & 78377,500 & 131027,500 &,- 906 &, 365 \\
\hline $\begin{array}{l}\text { ohranjanje obdelanosti kulturne } \\
\text { krajine }\end{array}$ & 79998,500 & 132648,500 &,- 371 &, 711 \\
\hline $\begin{array}{l}\text { ohranjanje sonaravnih sistemov } \\
\text { kmetovanja }\end{array}$ & 74820,500 & 127470,500 & $-2,008$ &, 045 \\
\hline $\begin{array}{l}\text { zaščita in ohranjanje kvalitetne } \\
\text { vode, ohranjanje tal in prsti }\end{array}$ & 67057,500 & 119707,500 & $-5,111$ &, 000 \\
\hline $\begin{array}{l}\text { ohranjanje avtohtonih in } \\
\text { tradicionalnih sort kmetijskih rastlin } \\
\text { in pasem živali }\end{array}$ & 72578,000 & 125228,000 & $-2,758$ &, 006 \\
\hline $\begin{array}{l}\text { zmanjševanje kmetijskega } \\
\text { obremenjevanja okolja (voda, zrak, } \\
\text { tla) }\end{array}$ & 68497,500 & 121147,500 & $-4,212$ &, 000 \\
\hline $\begin{array}{l}\text { nadzorovana uporaba gnojil in } \\
\text { fitofarmacevtskih sredstev }\end{array}$ & 63570,500 & 116220,500 & $-6,087$ &, 000 \\
\hline ustvarjanje novih delovnih mest & 81152,500 & 133802,500 &,- 003 &, 998 \\
\hline $\begin{array}{l}\text { zagotavljanje poseljenosti } \\
\text { podeželja }\end{array}$ & 80810,000 & 133460,000 &,- 111 &, 912 \\
\hline $\begin{array}{l}\text { mladi in izobraženi kmetje } \\
\text { izboljšanje prometne in druge } \\
\text { infrastrukture }\end{array}$ & 80151,000 & 205902,000 &,- 324 &, 746 \\
\hline $\begin{array}{l}\text { ohranjanje naravne in kulturne } \\
\text { dedišcine }\end{array}$ & 79286,000 & 205037,000 &,- 588 &, 557 \\
\hline izboljšanje kakovosti življenja & 75733,500 & 128383,500 & $-1,802$ &, 072 \\
\hline
\end{tabular}

\subsection{Zaznavanje razvoja kmetijstva v Sloveniji in ocena razlogov za takšen razvoj}

Kot zadnje nas je zanimal pogled ljudi na to, kako se je razvijalo trajnostno kmetijstvo v zadnjih desetih letih s treh vidikov, in sicer preskrbe s hrano, preživetja kmeta in ohranjanja okolja. Iz primerjave odgovorov (tabela 4) je razvidno, da obe skupini večinoma menita, da je šel razvoj na slabše, predvsem z vidika preživetja kmeta. Glede preskrbe s hrano je odstotek javnosti, ki meni da gre na slabše, manjši, medtem ko ravno obratno velja pri vidiku ohranjanja 
okolja. Zanimivo je, da obe skupini približno enako zaznavata razvoj v zadnjih desetih letih tudi glede prepričanja, da gre na bolje oziroma, da ostaja enako.

Tabela 4: Zaznavanje razvoja trajnostnega kmetijstva v zadnjih desetih letih $s$ treh vidikov

\begin{tabular}{|l|r|r|r|r|r|r|}
\hline & \multicolumn{2}{|c|}{ Preskrba s hrano } & \multicolumn{2}{c|}{ Preživetje kmeta } & \multicolumn{2}{c|}{ Ohranjanje okolja } \\
\cline { 2 - 7 } & kmetje \% & javnost \% & kmetje \% & javnost \% & kmetje \% & javnost \% \\
\hline gre na bolje & 24,4 & 30,5 & 11,1 & 8,5 & 33,3 & 22,6 \\
\hline gre na slabše & 54,6 & 46,1 & 74,1 & 71,3 & 41 & 54,3 \\
\hline ostaja enako & 21 & 23,4 & 14,8 & 20,2 & 25,6 & 23 \\
\hline
\end{tabular}

Mann-Whitney test pokaže, da se odgovori statistično ne razlikujejo med obema skupinama pri opredelitvah ali gre na bolje ali slabše glede različnih vidikov trajnostnega razvoja kmetijstva. $\vee$ obeh skupinah je delež tistih, ki menijo, da gre razvoj na slabše, največji.

Zaznavanje kmetov o razvoju kmetijstva se zdi glede na osredotočenost kmetijske politike $v$ zadnjih desetih letih zelo realno. Država naj bi v tem času vlagala sredstva predvsem v trajnostno rabo naravnih virov in ohranjanje krajine (okrog 80 mio EUR v letu 2010), manj v kakovost življenja na podeželju (okrog 60 mio EUR v letu 2010) in najmanj v izboljšanje konkurenčnosti kmetijsko prehrambnega sektorja (okoli 20 mio EUR v letu 2010). Od leta 2000 do 2010 naj bi se delež skupnih javnih sredstev za kmetijsko politiko povečal kar za štirikrat (Juvančič \& Slabe Erker, 2006). Tudi ekonomski podatki potrjujejo slabo stanje na ekonomskem področju. Kljub povečanju kmetijske proizvodnje je opazen trend zmanjševanja BDV. V obdobju 2000-2010 je delež BDV iz kmetijstva v Sloveniji padel za 0,8 odstotne točke, v povprečju držav EU-15 pa za 1 odstotno točko. Od leta 2002 do 2009 se je delež izdatkov za hrano v vseh izdatkih zmanjšal v Sloveniji za dobri 2 odstotni točki, pri čemer se večji delež izdatkov povezuje z uvoženo hrano. Sektor kmetijstva v Sloveniji že od leta 2005 naprej ni bil poslovno uspešen (razmerje med prihodki in izdatki je 0,9 oz. 0,8) (Eurostat, 2011).

Na drugi strani se zdi pesimizem splošne javnosti na področju doseganja okoljske trajnosti kmetijstva v tem trenutku pretiran, saj je v nasprotju z ugodnimi okoljsko-kmetijskimi dosežki in trenutno usmerjenostjo kmetijske politike.

Anketirance, ki so pri dveh zgornjih vidikih navedli, da gre razvoj na slabše, smo povprašali po razlogih, ki botrujejo takšni oceni (prim. grafikon 4). Največje razlikovanje povprečne ocene je pri trditvi o večji uporabi kemičnih sredstev, saj javnost meni, da je povečana uporaba le-teh razlog za slabši razvoj trajnostnega kmetijstva. Javnost je višjo oceno prisodila tudi trditvama, ki sta povezani s povečevanjem zaraščanja kmetijskih površin in odseljevanjem v mesta, medtem ko je od kmetov večjo povprečno oceno kot razlog za razvoj, 
Maja Klun, Renata Slabe Erker

ki gre na slabše, prejela trditev o nižjem dobičku in pomanjkanju finančnih spodbud (subvencij).

Spet se pokaže, da za to, da gre razvoj na slabše, splošna javnost pripisuje večjo težo okoljskim in krajinskim dejavnikom, kmetje pa ekonomskim dejavnikom.

Grafikon 4: Primerjava povprečnih ocen trditev javnosti in kmetov o tem, zakaj gre razvoj trajnostnega kmetijstva v zadnjih desetih letih na slabše

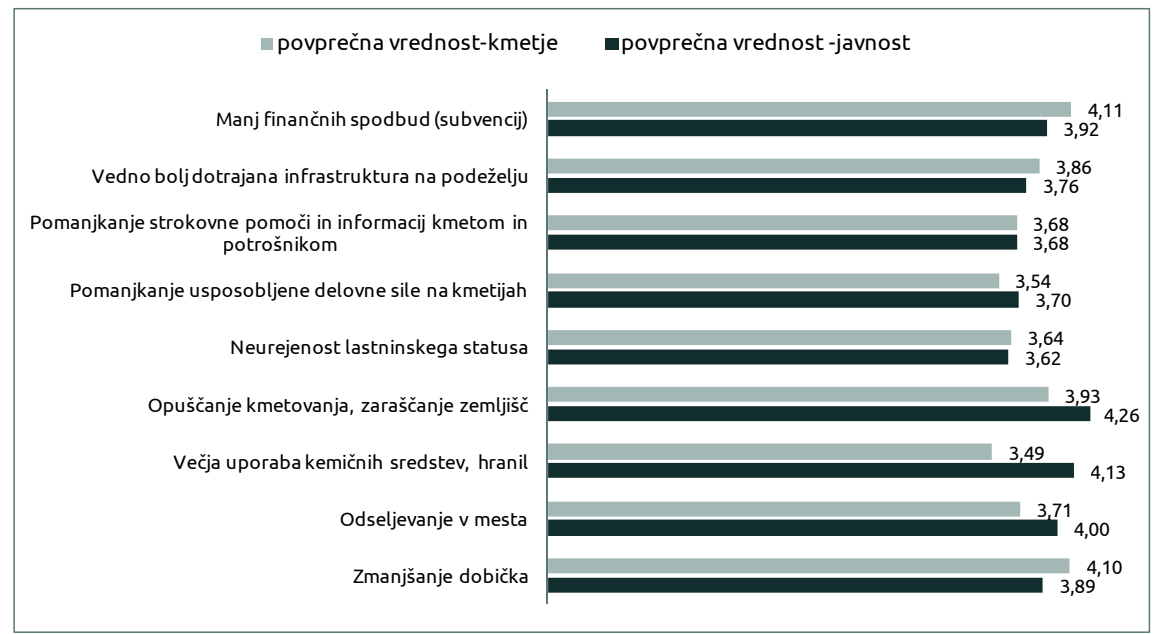

Tabela 5: Mann-Whitney test za trditve o razlogih, da gre razvoj trajnostnega kmetijstva na slabše

\begin{tabular}{|l|r|r|r|r|}
\hline & $\begin{array}{r}\text { Mann- } \\
\text { Whitney U }\end{array}$ & Wilcoxon W & Z & $\begin{array}{r}\text { Asymp. } \\
\text { Sig. } \\
\text { (2-tailed) }\end{array}$ \\
\hline Zmanjšanje dobička & 22352,500 & 59208,500 & $-2,833$ &, 005 \\
\hline Odseljevanje v mesta & 22815,000 & 41536,000 & $-2,469$ &, 014 \\
\hline $\begin{array}{l}\text { Večja uporaba kemičnih } \\
\text { sredstev, hranil }\end{array}$ & 18366,000 & 37087,000 & $-5,724$ &, 000 \\
\hline $\begin{array}{l}\text { Opuščanje kmetovanja, } \\
\text { zaraščanje zemljišč }\end{array}$ & 22591,500 & 41312,500 & $-2,688$ &, 007 \\
\hline $\begin{array}{l}\text { Neurejenost lastninskega } \\
\text { statusa }\end{array}$ & 25033,500 & 61889,500 &,- 820 &, 211 \\
\hline $\begin{array}{l}\text { Pomanjkanje usposobljene } \\
\text { delovne sile na kmetijah }\end{array}$ & 24447,000 & 43168,000 & $-1,251$ &, 707 \\
\hline $\begin{array}{l}\text { Pomanjkanje strokovne } \\
\text { pomoči in informacij kmetom } \\
\text { in potrošnikom }\end{array}$ & 25640,000 & 62496,000 &,- 375 &, 226 \\
\hline $\begin{array}{l}\text { Vedno bolj dotrajana } \\
\text { infrastruktura na podeželju }\end{array}$ & 24504,500 & 61360,500 & $-1,210$ &, 014 \\
\hline $\begin{array}{l}\text { Manj finančnih spodbud } \\
\text { (subvencij) }\end{array}$ & 22842,000 & 59698,000 & $-2,459$ & \\
\hline
\end{tabular}

42 Administration, Vol. X, No. 2/1012 
Ponovno smo za posamične trditve izdelali Mann-Whitney test. Iz rezultatov testa je razvidno (tabela 5), da se odgovori statistično značilno razlikujejo med obema skupinama anketirancev ravno pri omenjenih trditvah.

Večja usklajenost med skupinama je pri oceni razlogov ki botrujejo razmišljanju, da gre razvoj na bolje, saj so povprečne ocene skupin precej podobne (grafikon 5). Drugi del javnosti, ki meni, da gre razvoj vendarle v pravo smer, vidi zasluge za takšen razvoj na strani proizvodnje v največji meri prav v boljši praksi kmetovanja, na strani potrošnje pa v kupcih, ki povprašujejo po kakovostni domači hrani. Ljudje pripisujejo le malo zaslug za izboljšanje razvoja priseljencem na podeželje. Javnost (zlasti splošna) je očitno zelo polarizirana pri zaznavi napredka na okoljskem področju.

\section{Grafikon 5: Primerjava povprečnih ocen trditev javnosti in kmetov o tem, zakaj gre razvoj trajnostnega kmetijstva v zadnjih desetih letih na bolje}

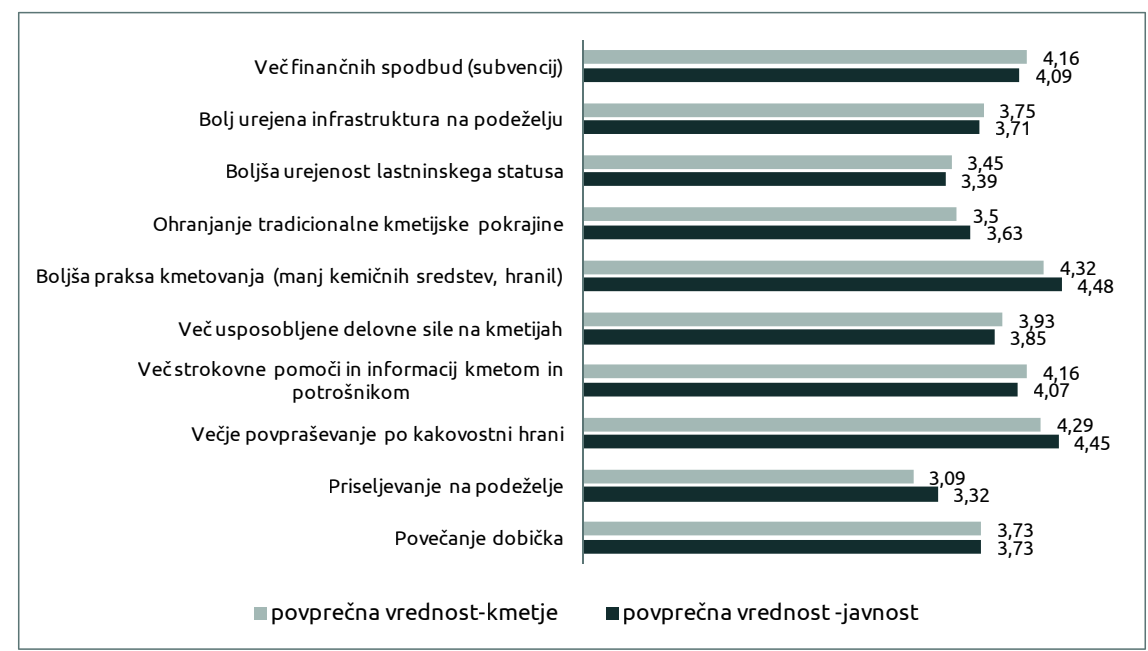

Tudi rezultati Mann-Whitney testa dokazujejo relativno enako vrednotenje razlogov obeh skupin anketirancev.

Glede na podatke o stanju okolja in zdravi hrani pa si kljub neenotnem mnenju in zaznavam javnosti upamo trditi, da se oba dejavnika spreminjata na bolje. To namreč dokazuje že hiter pregled nekaterih podatkov o stanju okolja. Tako se je na primer v zadnjih letih izboljšala bilanca dušika, t.j. razlika med vnosom ter odvzemom dušika s kmetijskih zemljišč, iz 101 kg N/ha v letu 2003 na 64 kg N/ha v letu 2007 (Eurostat, 2011). Povprečna poraba rastlinskih hranil je bila v obdobju 2000-2007 v Sloveniji dobrih 125 kg na hektar. Od leta 2000 je poraba rastlinskih hranil padala tako, da je znašala v letu $200716 \%$ manj kot leta 2002 (SURS, 2009). Prodaja fitofarmacevtskih sredstev se je v Sloveniji v obdobju 2000-2005 zmanjšala za približno $5 \%$ (Eurostat, 2011). Odziv kmetijskih gospodarstev na kmetijsko politiko, ki podpira širjenje ekološkega 
Maja Klun, Renata Slabe Erker

kmetovanja, je prav tako iz leta v leto večji. Površine zemljišč, namenjene ekološkemu kmetovanju, so se v obdobju 1999-2008 povečale od 2.400 ha na 29.836 ha oziroma od 0,5\% na 6,1\% vseh kmetijskih zemljišč v uporabi (ARSO, 2009). Da država namenja skrb vprašanju varne in kakovostne hrane, priča tudi podatek, da je delež izdatkov za raziskave in razvoj povezanih z varnostjo hrane v bruto družbenem proizvodu nekaj več kot pol odstotka, kar je popolnoma primerljivo z povprečjem EU-27 (0,53 \%) (Eurostat, 2011).

\section{Zaključek}

V Sloveniji, razen na deklarativni ravni, ni na razpolago strokovnih podlag, ki bi argumentirano prikazovale raven trajnostne naravnanosti kmetijstva in kmetijske politike. Prav tako je deficitarno raziskovalno področje podpora javnosti temu konceptu , ki se ga lotevamo v tem članku.

Preučevali smo mnenje širše javnosti in kmetov o pomenu trajnostnega kmetijstva v Sloveniji. Ugotovljeno je bilo, da se ljudem trajnostni razvoj kmetijstva zdi zelo pomemben, pri čemer javnost bolj izpostavlja okoljsko dimenzijo trajnosti, kmetje pa družbeno dimenzijo trajnosti, s poudarkom tudi na njihovem dohodkovnem položaju. Po mnenju obeh ciljnih skupin pa trajnostno kmetijstvo najbolj označujejo pojmi samooskrba s hrano, varna hrana in kakovostna hrana. To kaže na dobre obete za prodajo doma pridelane hrane v prihodnosti. Zato so v tem trenutku, ko trajnostne kmetijske prakse praviloma niso ekonomsko upravičene, državljani pa se že zavedajo zdravstvenih in okoljskih koristi kakovostne in varne hrane (kar v praksi nakupovanja še ni zabeleženo), obstoječe spodbude politike zelo dobrodošle. Tu mislimo na spodbude tako na strani proizvodnje, kot so na primer ukrepi za spodbujanje domače porabe, neposredna plačila za ekstenzivno rejo, za mlečno proizvodnjo v hribovskih območjih, podpore skupinam proizvajalcev pri dejavnostih informiranja in pospeševanja prodaje za proizvode, ki so vključeni v sheme kakovosti hrane (PRP - ukrep 133), kot na strani povpraševanja, npr. programi informiranja in promocije.

Velik pomen pa ljudje pripisujejo tudi ohranjanju okolja, ki bi ga lahko dosegli z manjšim obremenjevanjem okolja, z zaščito in ohranjanjem kakovostne (pitne) vode, tal in prsti, kar zahteva predvsem manjšo uporabo kemičnih sredstev oziroma nadzorovano uporabo gnojil in fitofarmacevtskih sredstev ter boljšo kmetijsko prakso. Vse to se uresničuje v ekološkem kmetovanju. Ukrepi politike, ki vplivajo na ta segment, pa se nanašajo predvsem na ukrepe za izboljšanje okolja in krajine (kmetijsko okoljska plačila in plačila za območja z omejenimi dejavniki). Tudi v praksi se ta vidik vedno bolj upošteva, medtem ko javnost očitno tega ne zaznava, oziroma je razdvojena pri zaznavanju te situacije. Pozitivne informacije o dogajanju na tem področju so zato nujne.

V raziskavi ugotavljamo, da javnost zaznava, da gre razvoj kmetijstva v Sloveniji z vidika preživetja kmeta na slabše. Kmetom je sicer zagotovljeno veliko finančnih pomoči, ki se kažejo v obliki različnih subvencij, a jih nekateri

44 Administration, Vol. X, No. 2/1012 
kmetje težje pridobijo in zato so odvisni le od financ, ki jih pridobijo s prodajo pridelane hrane. Tudi ekonomski podatki potrjujejo slabo stanje na tem področju. Statistično značilne razlike med splošno javnostjo in kmeti so se pokazale ravno pri dojemanju trajnostnega napredka kmetijstva na področju okolja. Splošna javnost je precej polarizirana. Po eni strani večina meni, da gre razvoj na področju okoljske trajnosti kmetijstva na slabše, čeprav kmetijsko okoljski kazalniki kažejo, da je dejansko stanje na tem področju v zadnjih letih izjemno napredovalo in je primerljivo z drugimi evropskimi državami. Po drugi strani pa velik del splošne javnosti (čeprav ne večinski) nasprotno pripisuje prav okoljskim faktorjem zasluge za razvojne premike na bolje. Primerjalno s tem so zaznave kmetov bliže realnosti in se dobro zavedajo šibkega področja kakovosti življenja in slabega dohodkovnega položaja kmeta. Ta ugotovitev kliče po tem, da bi se javnosti zagotovile uravnotežene in objektivne informacije.

Ideja o trajnostnem kmetijstvu je predmet razprav že zelo dolgo časa. Opaziti je določene premike $v$ to smer, vendar še zmeraj ne v tolikšni meri, kot bi bilo potrebno. Delež tistih, ki kupujejo ekološko pridelano domačo hrano, je namreč v Sloveniji še vedno nizek. Prodaja lastnih kmetijskih pridelkov in proizvodov na živilskih trgih je v letu 2010 znašala dobre 3 \% BDV kmetijstva (SURS, 2011). S tako šibko dejansko podporo potrošnikov trajnostnemu kmetijstvu je kljub pomoči države težko zagotavljati ekonomsko in socialno varnost kmeta. Pomembno je, da o tem ne govorimo samo na teoretični ravni ter da ne skušamo vsiliti ljudem način ravnanja samo preko predpisov, ampak moramo vplivati na prepričanja in vrednote ljudi, da bi lahko spremenili in opustili prevladujoče vzorce življenja in delovanja. To je zelo dolgotrajen proces, ki ga najlažje uresničimo z ustreznim vzgojnim in izobraževalnim sistemom. Ljudje bodo spremenili svoje vedenjske vzorce, če bodo ustrezno motivirani, informirani in ozaveščeni. K temu lahko zgledno prispevajo zajamčeni trgi za hitro pokvarljivo sadje in zelenjavo (npr. javni sektor).

$\checkmark$ raziskavi je bil poudarek na osebnih mnenjih, kaj si ljudje mislijo o posamezni stvari oz. posamezni funkciji trajnostnega razvoja kmetijstva, kar se da kvantitativno izmeriti samo z javnomnenjskimi anketami, ki pa kot vemo, niso najbolj objektivne. Poleg tega osebno mnenje ne odraža vedno dejanskega stanja oziroma je zaznavanje lahko drugačno od realnosti. Zato naše rezultate soočamo z dejanskim stanjem. Našo raziskavo bi lahko izboljšali tako, da bi jo opravili na večjem statističnem vzorcu, saj bi na podlagi tega potem lahko trdili, da so ugotovitve in mnenja posameznikov res takšna, kot smo ugotovili $v$ tej manjši raziskavi. Bilo pa bi zanimivo, če bi v nadaljnjih raziskavah preučili, kaj vpliva na mnenje ljudi, da je takšno kakršno je. Lahko bi se osredotočili na osebne vrednote ali pa na vplive različnih medijev na mnenje posameznika in s tem identificirali dejavnike, prek katerih je smiselno in možno spreminjati oziroma krepiti trajnostno zavedanje, proizvodne in potrošniške oziroma prehranjevalne vzorce. Verjamemo, da je na ta način možno doseči sinergijske učinke na ekonomskem, družbenem in okoljskem področju razvoja. 
Maja Klun, Renata Slabe Erker

Dr. Maja Klun je izredna profesorica na Fakulteti za upravo. Njeno primarno področje raziskovanja in znanstvenega ter strokovnega proučevanja so javne finance s poudarkom na davčnem sistemu, $k$ rezultatom usmerjeni proračun in merjenje učinkovitosti in uspešnosti javnega sektorja.

Renata Slabe-Erker je od leta 1995 zaposlena na Inštitutu za ekonomska raziskovanja, Ljubljana. Kot raziskovalka je aktivno sodelovala in koordinirala številne raziskovalne projekte na področju okoljske ekonomike in ekonomike varstva narave in trajnostnega razvoja.

46 Administration, Vol. X, No. 2/1012 


\section{Literatura in viri}

- Aerni, P. (2009). What is sustainable agriculture? Empirical evidence of diverging views in Switzerland and New Zealand. Ecological Economics (68), 1872-1882.

- Alonge J. A. \& Martin, R. A. (1995). Assessment of the Adoption of Sustainable Agriculture Practices: Implications for Agricultural Education. Journal of Agricultural Education (36), 34-42.

- ARSO (2009). Kazalci okolja v Sloveniji. Ljubljana: Ministrstvo za kmetijstvo in okolje.

- Bhutto, A. W., \& Bazmi, A. A. (2007). Sustainable agriculture and eradication of poverty in Pakistan. Natural Resources Forum (31), 253-262.

- Eurostat (2011). Economic Accounts for Agriculture, EC.

- Evropska Komisija (2012). Kmetijstvo in razvoj podeželja. Skupna kmetijska politika na dlani. Pridobljeno 20. 2. 2012, s http://ec.europa.eu/agriculture/ publi/capexplained/cap_sl.pdf (5. 2. 2012).

- Hosseini, S. J. F., Mohammadi F. \& Mirdamadi, S. M. (2011). Factors affecting environmental, economic and social aspects of sustainable agriculture in Iran. African Journal of Agricultural Research (6), 451-457.

- Ikerd, J. E. (1994). Systems Research in Sustainable Agriculture: Economics, Ecology, and Quality of Life. American Journal of Agricultural Economics (76), 1271.

- Juvančič, L. \& Slabe Erker, R. (2006). Policy practice vs. public Perception: does the support for multifunctional agriculture in Slovenia deliver the right thing? Journal of Central European Agriculture (7), 565-570.

- Mann, H. B. \& Whitney, D. R. (1947). On a test of whether one of two random variables is stochastically larger than the other. Annals of Matematical Statistics (18), 50-60.

- Napier, T. L., Thraen, C. S., Gore, A., \& Goe, W. R. (1984). Factors affecting adoption of conventional and conservation tillage practices in Ohio. Journal of Soil and Water Conservation (39), 205-209.

- Plut, D. (2004). Zeleni planet? Prebivalstvo, energija in okolje v 21. stoletju. Ljubljana: Didakta.

- Public Law 101-624, Title XVI, Subtitle A, Section 1683

- Rahman, S. (2003). Environmental impacts of modern agricultural technology diffusion in Bangladesh: An analysis of farmers' perceptions and their determinants. Journal of Environmental Management (68), 183-191.

- Rao, N. H. \& Rogers, P. P. (2006). Assessment of agricultural sustainability. Current Science (91), 439-448.

- Rao, P. P. \& Hall, A. J. (2003). Importance of crop-livestock system in India and farmers' perceptions of fodder quality in coarse cereals. Field Crops Research (84), 189-198.

- Special Eurobarometer (2008). Europeans, Agriculture and the Common Agricultural Policy. European Commission, Brussels. Pridobljeno 20. 2. 2012, s http://ec.europa.eu/agriculture/survey/2008/fullreport_en.pdf.

- SURS. SI-STAT podatkovni portal. Pridobljeno december 2011, s http://pxweb. stat.si/pxweb/Dialog/statfile2.asp

- Swanson, L., Camboni, S. \& Napier, T. (1986). Barriers to adoption of soil conservation practices on farms. In Lovejoy, S. \& Napier, T. (Eds.). Conserving soils: Insights from socioeconomic research. Ankeny, lowa: Soil Conservation Society of America. 
Maja Klun, Renata Slabe Erker

- Tathdil F. F., Boz I. \& Tatlidil, H. (2009). Farmers' perception of sustainable agriculture and its determinants: a case study in Kahramanmaras province of Turkey. Environment, Development and Sustainability (11), 1091-1106.

- Taylor, D., Mohamed, Z., Shamsudin, M., Mohayidin, M., \& Chiew, E. (1993). Creating a farmer sustainability index: A Malaysian case study. American Journal of Alternative Agriculture (8), 175-184.

- Zakon o kmetijstvu (ZKme-1). Ur. list RS, št. 45/2008. 